\title{
Risk Factors of Parastomal Hernia and Creation of an Ostomy
}

\author{
Jin Kwon Lee, Won Kyung Kang \\ Department of Surgery, Seoul St. Mary’s Hospital, The Catholic University of Korea College of Medicine, Seoul, Korea
}

\section{See Article on Page 241-246}

A parastomal hernia at the site of a permanent end colostomy is a common and troublesome complication, and its incidence is estimated to be up to $48.1 \%$ [1]. The aim of this study was to analyze the incidence of and the risk factors for a parastomal hernia. In this study, the plausible risk factors for a parastomal hernia were as follows: female gender, age over 60 years, body mass index more than $25 \mathrm{~kg} / \mathrm{m}^{2}$, and hypertension. Other risk factors from other studies were obesity and waist circumference greater than $100 \mathrm{~cm}$. Although the prophylactic use of mesh may be an option for those patients requiring a permanent stoma [2], the efficacy of using prophylactic mesh for patients with a permanent stoma is a subject of debate due to mesh-associated complications $[3,4]$. In this study, the parastomal hernias were assessed by using computed tomography scans. No objective grading-system was used, and no subject symptoms were noted. Also, no descriptions of the stoma-creation techniques used by the authors were given.

The key factor to prevent a parastomal hernia is the surgical accuracy of stoma creation. As general rules, stomas should be placed through the rectus sheath for additional muscular support, fascial openings should be fit to the size of the exteriorized bowel circumference, prophylactic application of mesh may only be considered for those patients requiring a permanent stoma, and an extraperitoneal tunneling of the bowel may be considered [4]. The procedure of an end colostomy is usually performed as a final surgical procedure; the surgeon should do his or her best to create an appropriate stoma because the incidence of a "too loose stoma" might be double the incidence of a "too tight stoma."

Further detailed studies regarding the degree of herniation and standardization of the stoma-creation method may be helpful for focusing on the risk factors. This study appears to support the prophylactic use of mesh in high-risk patients.

\section{REFERENCES}

1. Carne PW, Robertson GM, Frizelle FA. Parastomal hernia. Br J Surg 2003;90:784-93.

2. Rubin MS, Schoetz DJ Jr, Matthews JB. Parastomal hernia. Is stoma relocation superior to fascial repair? Arch Surg 1994;129:413-8.

3. Devlin HB. Peristomal hernia. In: Rob C, Smith R, Dudley H, Pories W, Carter DC. Rob \& Smith's operative surgery. Alimentary tract and abdominal wall., 1, General principles, oesophagus, stomach, duodenum, small intestine, abdominal wall, hernia. 4th ed. London: Butterworths; 1983. p. 441.

4. Hyman N, Nelson R. Stomal complication. In: Wolff BG, Fleshman JW, Beck DE, Pemberton JH, Wexner SD, editors. The ASCRS textbook of colon and rectal surgery. New York: Springer; 2007. p. 643-52.
Correspondence to: Won Kyung Kang, M.D.

Department of Surgery, Seoul St. Mary's Hospital, The Catholic University of Korea College of Medicine, 222 Banpo-daero, Seocho-gu, Seoul 137-701, Korea

Tel: +82-2-2258-6104, Fax: +82-2-595-2822

E-mail: wonkkang@catholic.ac.kr

(c) 2012 The Korean Society of Coloproctology

This is an open-access article distributed under the terms of the Creative Commons Attribution NonCommercial License (http://creativecommons.org/licenses/by-nc/3.0) which permits unrestricted noncommercial use, distribution, and reproduction in any medium, provided the original work is properly cited. 